\title{
A Study of Social Integration through Sports Program among Migrant Women in Korea
}

\author{
Se-Joong Lee ${ }^{1}$, In-Sung Yeo ${ }^{1}$ and Byoung-Wook Ahn ${ }^{2, *}$ (]) \\ 1 Department of Sport of Industry Studies, Sinchon Campus, Yonsei University, Seoul 03722, Korea; \\ sejoong99@yonsei.ac.kr (S.-J.L.); isyeo@yonsei.ac.kr (I.-S.Y.) \\ 2 Department of Leisure Marine Sports, School of Marine-Sports, Seosan Campus, Hanseo University, \\ Seosan-si 31962, Korea \\ * Correspondence: bwahn75@hanseo.ac.kr; Tel.: +82-41-660-1547
}

Citation: Lee, S.-J.; Yeo, I.-S.; Ahn, B.-W. A Study of Social Integration through Sports Program among Migrant Women in Korea. Societies 2021, 11, 116. https://doi.org/ $10.3390 / \operatorname{soc} 11040116$

Academic Editor: Gregor Wolbring

Received: 6 August 2021

Accepted: 17 September 2021

Published: 23 September 2021

Publisher's Note: MDPI stays neutral with regard to jurisdictional claims in published maps and institutional affiliations.

Copyright: (c) 2021 by the authors. Licensee MDPI, Basel, Switzerland. This article is an open access article distributed under the terms and conditions of the Creative Commons Attribution (CC BY) license (https:// creativecommons.org/licenses/by/ $4.0 /)$.

\begin{abstract}
This study aimed to examine sports programs at multicultural family support centers located throughout the country and present the possibility of social integration through the sports programs. The multicultural sports program showed that it affected the ability of migrant women in international marriages to socially integrate with other women like themselves, their husbands, and the natives, and also affected themselves. In order to clarify the purpose of the research, indepth interviews were carried out. The collected material was transcribed, encoded, and classified. The results were analyzed from the perspective of sports' physical, psychological, and social functions. This social integration was shown to be more effective than any other program at the multicultural family support center. Regarding their relationship with their husbands, the program provided opportunities for deepening their mutual understanding. The sports program was also utilized as a place of leisure for the women as well, and it was discovered that sports activities were being used as a means of resolving stress. The migrant women's life radius and interpersonal relations were small due to their limited linguistic abilities. They provided opportunities to form confidence in their Korean life.
\end{abstract}

Keywords: social integration; multi-culture; sports program; migrant

\section{Introduction}

According to Statistics Korea, only 270,000 foreigners were living in Korea in 1995, but that number increased to 740,000 in 2005, to more than 800,000 by April 2006, and reached one million in August 2009 [1]. In 2020, the number of foreign residents was $2,216,612$, exceeding $4.2 \%$ of the total population. The figures are a clear indication that Korea is becoming a multicultural society.

The UN Committee on the Elimination of Racial Discrimination pointed out in 2007 that in the Korean society, the notion of racial superiority, along with the use of terms such as "a single-race", "pure bloodline", and "mixed-blood" was widespread [2]. The report discussed in detail the human rights problems of children born to migrant workers, foreign spouses, and international marriages, and criticized Korea's jus sanguinis ("right of blood") culture. In particularly, a survey of Korean perceptions showed that the population was generous to migrants from advanced countries such as the United States and Europe, but had negative views on migrants from developing countries, including China and Southeast Asia, believing that they would damage the purity of Korean society [3]. Due to the increasing number of survival-related crimes arising from economic stagnation and the surging uncertainties regarding the future, Koreans do not have friendly views of migrants from China and Southeast Asia, and some even perceive the migrants as intruders who are destroying the rights and culture of the Koreans [4].

Multiculturalism is at the core of the effort to overcome differences with migrants and achieve social integration. Multiculturalism refers to a philosophical system that 
aims to enable diverse ethnic and racial groups in a society to mutually recognize, respect, and coexist with each other's differences based on different ethnic backgrounds, rather than assimilating them into a single culture [5]. Korea is using the example of many countries that have experienced multiculturalism in its effort to establish a proper multicultural society, but the approach is showing limitations in many areas. In Western European countries, multiculturalism has been progressing at a leisurely pace over a long period of time, but in Korea, the government has been making earnest attempts at multiculturalism while still lacking sufficient insight on multiple cultures in order to respond to the rapid increase in the number of migrants. For this reason, government policies have resulted in trying to assimilate migrants into Korean culture rather than promoting exchange and understanding between various cultures, and in that process, causing additional problems, such as unfair treatment of migrant workers, human rights violations, difficulties in international marriages with migrant women, and children of international marriages experiencing socio-cultural adjustment issues. The efforts to establish a proper multiculturalism in Korea as a means of social integration have thus far been a failure. So, Korea also needs to have a variety of views on multiculturalism.

With the increase in migrants, Korean society is gradually changing into a multicultural society. Similar to a rapidly aging society becoming a new social problem in Korea, social integration through changing social views on the rapidly increasing number of migrants and properly establishing multiculturalism is also an important issue that Korean society needs to deal with. Given this need, research in Korea on social integration through multiculturalism began to be actively carried out in the late 1990s. As the problems of migrants became more visible, various studies have been carried out from different perspectives in many disciplines, including sociology, family studies, administrative studies, education, anthropology, and social welfare. It is encouraging that academic research is still being carried out on ways to establish proper multiculturalism; however, additional studies on diverse and complementary approaches to addressing the subject must be carried out.

Sports can be seen as performing an important function as a form of social integration policy. From existing studies carried out in North America and Germany, regions already having experienced multiculturalism, it is well documented that sports programs contribute to social integration. Sports speak a universal language, and anyone can participate regardless of their religion, class, age, or gender, enabling them to naturally interact with others. Through physical activity, people can reduce mental stress and increase their understanding of others in the local community as they cooperate and compete with them [6]. Because of these characteristics, sports can play a huge role in promoting multiculturalism for the purpose of social integration. With respect to the social integration function of sports, the spotlight should be drawn to the fact that members of society can be united and group identification can be established through sports. The issue of integration in sports rests on the concern of how sports contribute to producing and strengthening of social relationships, the same relationships that induce members of the society to continually and positively engage in their work and day-to-to-day living. Certain characteristics of sports contribute to social unity and group harmony. First, the picture of a game with a clear start and end is simple and clear in comparison to social life in general. Second, in real life, one's foe is not clear, whereas the opponent is easily distinguished in sports. Third, there exists a clear goal of victory in sports. Fourth, the final result is clear since scores decide victory or defeat [7]. Such social integration of sports appears equally in participatory sports involving direct participation as well as spectator sports. In the case of spectator sports, they help create a sense of unity by producing common emotions for regional and national teams that go beyond the level of the individual. Sports serve as a catalyst for promoting exchange and communication between people in proximity to each other, such as for family members, neighbors, and school and local community members. In such a role, sports act as a link that creates a network of human relationships and connectivity between individuals. In other words, people experience psychological consensus through sports. Sports can be viewed as promoting the same goals of social 
integration that a program in multicultural education is pursuing, in that people who participate in sports activities can purge their emotions of aggressiveness or hostility, become more social, and learn the benefits of sportsmanship. Studies performed by Muller et al. [8], Henry [9], and others have specifically presented sports as a potential social integration mechanism, and this suggests that sports can be used as a tool for multicultural education. Karin et al. reported that both leaders and participants highlighted how the activities enhance feelings of trust despite racism in society and how the leaders work to create relationships and to make the activities safe spaces [10]. Sine and Annette found that the non-state actors' (and in particular the sports associations') rationality of strengthening local clubs through civil integration diverges from the municipal authorities' welfare policy preoccupation of engaging ethnic minority children and children in activities, and the social policy interest in education expressed by the housing organization [11].

Because sports do not require a high level of language skills from the participants, they can provide the participants with various experiences and tasks, give immediate feedback, and be a potentially useful teaching tool for multicultural education. As the strengths and merits of sports participation in multicultural education began to receive more attention, many European countries started to actively carry out research on multicultural sports education with the support of the European Union $[8,9,12]$. As such, special attention should be given to multicultural programs utilizing sports being actively carried out in Europe and centered around Germany.

Until now, however, the sports world in South Korea has been very passive in its approach to multiculturalism, and related studies are also lacking. Considering the social integration function of sports, examining the possibility of approaching and realizing multiculturalism in South Korea through sports and using the results to supplement policies on multiculturalism can be viewed as being necessary for successful social integration programs for multicultural families across the country.

So, with the increasing practice of a five-day workweek in South Korea, leisure activities, including those promoting well-being, have been receiving a lot of attention lately. Using sports to approach multiculturalism will provide new information in Korean society. Furthermore, Korea is also expected to provide a basis for the development of a multicultural society like advanced nations.

\section{Method}

\subsection{Preliminary Investigation}

For the study's preliminary investigation, the multicultural programs currently administered at various multi-cultural centers nationwide were examined. In particular, 119 multicultural family support centers consigned to the Ministry of Gender Equality and Family under government sponsorship were examined. The specific questions and topics investigated were (1) the current state of the multicultural programs being administered, (2) the reasons for a sports program not emerging not being included in the curriculum of a given multicultural program, (3) the limitations of the current multicultural program, and (4) the possibility of a sports program being part of the multicultural program.

\subsection{Study Participant Organization}

The "S Multicultural Family Support Center" was chosen as the organization satisfying these various conditions. This name was chosen to guarantee anonymity rather than using its formal name. Along with the details of the study, the researcher submitted to the center a proposal to set up a new sports program, and under the consent of the director of the center, the researcher was able to undertake the study. The center provided active support for the study program, with the management showing continued interest and goodwill throughout the duration of the study. The S Multicultural Family Support Center was established in 2008 and has 658 members, which is more than other organizations. As an institution operated by $\mathrm{S}$ University, it has gym facilities for sports activities, 
and above all, it was the institution that showed the most favorable position when proposing the research.

\subsection{Participants}

After obtaining the consent of the director of the $S$ Multicultural Family Support Center, a sports program was established as a part of its multicultural program curriculum. Applications for those wanting to participate were sought, with the number of participants being limited to 10 . The restriction of having a maximum of 10 participants was decided after carefully considering the need for the smooth running of the program along with the existing limitations in space where the sports program could be administered. The program proceeded with the 10 participants in the order of their submitted application. Thereafter, the data from 10 people who participated on a relatively steady basis for 7 months and actively took part in the interviews performed periodically over the duration of the program were included in the final data analysis. The number of study subjects was small because the subjects suitable for various conditions were selected to identify the purpose of the study. The Korean college students who joined in the middle or later stages of the program were also included as participant subjects in the study, and the interview details of 3 students who understood the purpose of the study and continuously participated in the interviews were also used in the data analysis. The basic information of the study participants is presented in Table 1 below. To guarantee anonymity, the actual names were not used and were substituted with the designation "Participant".

Table 1. Basic information of the participants.

\begin{tabular}{cccccc}
\hline No. & Name & Nationality & Age & Marital History & Children \\
\hline 1 & Participant 1 & China & 29 & Married 5 years & None \\
2 & Participant 2 & China & 36 & Married 11 years & 1 \\
3 & Participant 3 & Thailand & 36 & Married 10 years & 1 \\
4 & Participant 4 & Japan & 42 & Married 14 years & 2 \\
5 & Participant 5 & Philippines & 24 & Married 2 years & 1 \\
6 & Participant 6 & Philippines & 23 & Married 9 months & None \\
7 & Participant 7 & China & 28 & Married 18 months & 1 \\
8 & Participant 8 & Indonesia & 26 & Married 10 months & None \\
9 & Participant 9 & Mongolia & 32 & Married 7 years & 2 \\
10 & Participant 10 & Philippines & 20 & Married 6 months & None \\
11 & Participant 11 & Korea & 21 & Single & Sub-researcher 1 \\
12 & Participant 12 & Korea & 21 & Single & Sub-researcher 2 \\
13 & Participant 13 & Korea & 25 & Single & Sub-researcher 3 \\
\hline
\end{tabular}

\subsection{Sports Program}

For this study, a sports program was developed. In particular, the aim was to discover the influence and the effects of a sports program on women in multicultural families. The sports program was used for the social characteristics of sports, allowing it to be non-linguistic, and was judged, more than any other program, to influence the acculturation process of multicultural women. The multicultural sports program was carried out with the help of the S Multicultural Family Support Center. A gymnasium at S University was leased and the program's classes were badminton and table tennis. Initially, only badminton was offered but after two months or so, table tennis was added after receiving suggestions from the participants. Table tennis was possible since there were two table tennis tables available at the gymnasium, and as for badminton, it was played on four courts.

\subsection{Researcher as a Tool}

With respect to human and social research, the separation between the researcher and the research subject cannot be absolute since the researcher is in the same social context as the research subject. Moreover, the influence of the researcher's personal viewpoint and 
political stance cannot be eliminated completely. A researcher's personal experience may be a necessary factor to explain social interaction $[13,14]$. Therefore, the researcher was used as only a part and a tool of the study for the entire study period. The researcher collected data while observing the entire process. This was from the preliminary preparation period to the end of the program. The researcher went through the work of interviewing the subjects, recording observations, and writing self-assessments. The researcher recognized changes taking place in the participants as well as their environment and atmosphere while the multicultural sports program was being administered. To discover interesting points in this process of change, the researcher focused on collecting data.

\subsection{Data Collection}

\subsubsection{Participatory Observation and Field Notes}

In this study, the researcher also served as the administrator of the program. The researcher, serving as the badminton instructor, visited the study site once a week for $2 \mathrm{~h}$ and ran the program with also observing the participants, taking observation notes, and collecting data. Data collection was done by making brief notes on what the researcher perceived at the study site or by recording voice memos appropriate for given situations. After the class, the researcher stayed for about an hour to summarize the findings of that day and made daily field notes on any interesting points.

\subsubsection{Camcorder Recorded Data}

Using a camcorder, the researcher made recordings during the program sessions, and the recorded material was used to supplement data, obviating gaps in observations or note taking at the site. In interpreting the situations arising at the site, the video data helped resolve parts that the researcher misunderstood or failed to discover. A camcorder was also used to record feedback from the participants.

\subsubsection{Interview Data}

Periodic in-depth interviews were done on the program subjects participating in the study. The participants were migrant women in international marriages. An in-depth interview allows better access to an individual's attitude and changes in thinking and perception, which are difficult to grasp through only a questionnaire survey (Table 2). An in-depth interview is also considered to be effective for understanding the historical events or social structure affecting the individual. An in-depth interview is administered based on the interaction between the researcher and the study participant; however, the researcher prepares the questions of the interview only in an approximate way, and it can be more personalized than a questionnaire survey in which the questions are structured in an orderly manner and are prepared in advance.

Table 2. Semi-structured questions.

\begin{tabular}{cc}
\hline ID & Questions \\
\hline 1 & Do you have fun in sports programs? \\
2 & Do you think sports programs are helpful for your life in Korea? \\
3 & Do you think a sports program is helpful for personal development or family reconciliation? \\
4 & What has changed since participating in the sports program? \\
5 & If you were to expand the sports program further, what sports would you like? \\
\hline
\end{tabular}

An interview involves a continuous approach where the questions given to the interview subject during the investigation stage are chosen and modified often as dictated by the given moment [15]. Hence, a non-structured interview method was used at the initial stage of the study to broadly approach the subject's story, and then a semi-structured interview method was used to approach the topics that the researcher wanted to discuss [16].

The interviews were generally carried out in Korean, and for some Chinese and Japanese women who had difficulty communicating, Chinese and Japanese students study- 
ing in Korea were hired part-time to help with the interview. For women who could communicate better in English, such as those from the Philippines, the interviews were carried out in English, and if there was difficulty in communication, the assistant teachers at the multicultural family support center provided help in translation.

The shorter interviews were $15 \mathrm{~min}$ long and the longer ones took up to $1 \mathrm{~h}$. The interview duration was based on the participant's language abilities and schedule for the day. In addition, group interviews were also done from time to time and mostly women of the same nationality agreed to participate. All interview results were transcribed and documented.

\subsubsection{Online Data}

In order to help improve the subjects' skills and increase their sense of closeness during the program, scenes of sports participation and individual images were recorded in video and in pictures. This recorded material was made available on a dedicated webpage and used to induce active online communication as well as curiosity. In addition, by providing space below the photos for comments, an opportunity was provided for the individuals to actively express their thoughts online, and the responses to these postings played a valuable role in creating a positive atmosphere with the instructional lessons.

\subsubsection{Documentary Data}

Personal information collected during the study and the basic data held by the center were used for the study. Best efforts were made to maintain the confidentiality of the participants as required by adherence to research ethics.

\subsection{Self-Assessment Journal}

To effectively manage the study, the researcher wrote a compulsory self-assessment journal during the study period. Any difficulties arising during the administration of the program and the measures for resolving them, as well as changes in the researcher's perception or feeling, were recorded in the self-assessment journal. This was a measure to overcome any bias that the researcher may have had during the process of running the program, and it was also part of the effort made to obtain a more intimate understanding of the subjects.

\subsection{Ethics Statement}

We offered the participant the following consent statement and they provided consent to participate in the study: "I understand the purposes and length of this research study. I also understand that I can refuse to participate in this research study at any time. I agree to allow the researchers to use my personal information obtained from interviews and daily observations for the purposes of this study".

\subsection{Data Analysis and Interpretation}

\subsubsection{Qualitative Data Analysis and Interpretation}

The researcher interpreted the qualitative data based on the content analysis of the transcribed data obtained through participatory observations and field notes, as well as a self-assessment journal, video analysis, webpage analysis, and in-depth interviews. To eliminate any bias from the researcher when performing the content analysis, another person in the major research area was chosen to provide a second opinion, and this was deemed helpful in analysis and interpretation [17]. For data analysis, transcription, encoding, and categorization were performed. The transcription collected data from the field and recorded the data cleanly and systematically for subsequent analysis. Coding is a process of iteratively analyzing the contents of all transcribed data continuously and cyclically. In addition, we tried to solve research problems through a reflective inquiry process. The categorization process was categorized based on field observations and in-depth interviews through themes or meaning-living processes. 


\subsubsection{Reliability and Validity of the Study}

Since a qualitative study is not a study with the aim of generalizing from a sample group, unlike an experimental study, this study had the characteristics of not requiring specimen representations or statistical or analytical generalizations [18]. Miles et al. pointed out that during research, in order to inhibit the subjective biases of researchers and effectively interpret their research experiences, special structures are needed to suppress their personal opinions [19]. As such, in this study, the following efforts were made: (1) Effort was made to attain reliability in the interpretation of the qualitative data by performing the triangular checking of member reconfirmation, self-assessment journal writing, and peer assessment; (2) effort was made to reduce interpretation error by using a variety of data sources such as a participatory observation journal, field notes, in-depth interviews, a self-assessment journal, documents, and webpage postings; (3) to verify the members, continuous mutual verification work was done with the instructors at the multicultural center; and (4) in addition, to reduce misunderstanding in data interpretation, peer assessment was implemented. The data analysis was done together with peers consisting of a sports major and a social and cultural studies major. The researcher made efforts through these methods to increase the validity and reliability of the study and took pains to minimize any bias particular to the researcher.

\section{Results and Discussion}

\subsection{Social Function of Sports: Social Networking, Social Integration, Instilling a Sense of Fellowship, and Education}

Married migrant women are women who have left their country of birth and married and settle in Korea. Most migrant women in international marriages who come to Korea have limited Korean language ability, and consequently their social activities are greatly restricted. The migrants in international marriages who met at the multicultural family support centers were sympathetic and relied on each other as peers who were in the same situation. They exchanged information about Korean life and formed their own network.

We talk in class-the Korean language class. We also talk in the computer class. The self-help meeting is not a class. It's just a gathering where we chat. It's not for learning. But it's fun when us Chinese women get together by ourselves. We go to the karaoke and also go out to eat together. The classes are fun, but going out together to eat after class is more fun.

(Participant 2)

At the self-help meeting, we prepare mostly cultural events or the children's puppet plays. We do events. And so, we get together. If we just get together, I get asked at home what I did and my husband chastises me for only chit chatting. But if I say, we prepared for an event or a performance, there's no complaint. Even my husband has seen us perform traditional dances. And in this way, we get together to share stories and talk.

(Participant 1)

At the local multicultural family support centers, the migrant women in international marriages participated more actively in the Korean language and computer classes and the self-help meetings where they could talk about similar situations they faced. The self-help meeting in particular was shown to serve as a forum of communication through which the women relied on each other to overcome cultural stresses or difficulties or worries arising from living in a foreign country. It had the qualities of a cultural space in which knowledge and information needed for living in Korea were exchanged, and at times, where dissatisfaction and complaints were aired.

Adapting to Korean life is the primary goal of a computer class or a Korean language class, but there is little opportunity for students to actively express their opinions. However, a self-help meeting is a major resource for migrant women in international marriages, as it allows participants to actively tell their own stories. According to Niccolo et al., caregivers often complain that they do not have the necessary skills to be able to prevent or 
understand any deterioration in the health of a family member, but this also has consequences on the mental health of caregivers, as they usually feel unsuited to their duties [20]. The multicultural sports program, as it was implemented, was found to serve a role similar to a self-help meeting for these women. In the beginning, the program was run like a class, but as it was $2 \mathrm{~h}$ long, break times were given, and during the breaks, the women gathered characteristically to talk, indicating that the sports space could develop into something similar to a self-help meeting. These self-help meetings could be viewed as part of the educational function of sports [21]. Sports activities can facilitate migrant women to share their experiences and information, thus improving their relationships.

It's hard to play badminton without a break. And it's too hot in here. You sweat so much, just like this, even after playing just one game. Just sitting and watching 000 (Participant 7) and 000 (Participant 9) play is fun. They make me laugh. I'll take one more break and then go play. I'm so tired; I can't get up now.

(Participant 5)

I met 000 (Participant 6) here. Not all Filipinas are close. 000 (Participant 6) was friends with only 000 (Participant 5). But now, we talk together a lot. She talks to me like an older sister at home, and when I call about my husband hitting me, she gives me advice. When I don't know what to do, I can call her and she has the answer for me.

(Participant 10)

Clubs in Korea go beyond the specific goal of being gathering place for various sports activities, and also function as a social arena to promote friendship among the members. Likewise, it was confirmed that the multicultural sports program could be an arena for social interaction through sports. About 20 women in particular participated in the class and by nationality, there were one or two in the smallest group and seven to eight in the largest. Initially, competition between different countries became a natural format for playing badminton and table tennis. During such games, intense cheering for one's own side could be observed. Such forming of a sense of unity and belonging to a team, with team members providing and receiving help, was a strength of sports that showed an outstanding effect in uniting the migrant women who initially felt awkward with each other.

Teacher, you assigned the teams. China is always good in badminton. That's why 000 (Filipina) is not doing well. 000 (Participant 7) and 000 (Participant 2) continue to win today. No one else will win at this rate. Mongolia is really bad. Isn't China really good?

(Participant 1)

000 (Participant 9) is really good in sports. No one can beat her. We need to be on the same team. I'm bad, because I can't serve right. 000 (Participant 9) can hit far because she's strong, isn't she? Next time get 000 (Participant 9) to play against China (Participant 2). It will be fun.

(Participant 6)

For me, playing against Thailand (Participant 3) is most fun. We played four times today, and I won two and lost two. Our height is similar. Thailand did not come last time. Can you make the teams same as today's? Today was most fun. I want to play Thailand again next time.

(Participant 5)

In addition, women from different nationalities were placed on the same teams to play doubles. It was found that in the beginning no reaction was shown even when a partner made mistakes, but as they became immersed in the game, they began to express feelings about success and failure during the game. The awkward and unfamiliar atmosphere rapidly dissipated through the sport games and a sense of unity of being on the same team developed. It could be seen that through the sport games, a new, small culture of their own was created while playing. 
In the case of countries that have already experienced a multi-ethnic society, that is, the failure of immigrants to integrate into society and major countries suffering side effects, we need to make efforts to integrate migrants into society [22]. Through examples from many advanced countries focusing on the social integration function of sports and actively utilizing sports to culturally integrate immigrants or expand the rights and interests of women mainly through the activities of the UN, UNESCO, or the EU, social integration from participating in sports is one of the most important benefits [23]. The social integration function of sports is doubly effective because of the non-linguistic aspect of sports, and in this study as well, it was easy to witness how the non-linguistic characteristic of sports enabled women from different countries to overcome their linguistic barriers and become close.

It's fun to play together. When the teams were formed according to country, China always won. But since different countries are playing together, the teams are becoming more equal. And 000 (Participant 5) and 000 (Participant 6) always stuck together. Playing in this combination is fun too, and we become closer.

(Participant 8)

During the first month of the class, women were observed gathering and going home after class in groups according to nationality. However, after the teams were reassigned with mixed nationalities, the distance between the women of different nationalities narrowed as time passed, and they were even observed going to convenience stores together after class. Previously, as discovered through interviews, although they knew each other from the same Korean language class, they only recognized each other's presence and did not engage in much conversation. That atmosphere disappeared with the badminton and table tennis classes. An example is of China 1 and Thailand 1; although they each rode the same bus home, they consciously tried to ride the bus separately by walking at different speeds, but this behavior disappeared by the middle of the sports class they participated in.

This is in line with the findings of previous studies reporting that participation in sports had a positive effect on social interactions [24,25]. In fact, the migrant women in international marriages found out that the multicultural sports program provided a social arena for sharing information on child rearing, relationships with their in-laws, and relationships with their husbands. In addition, these women, placed under the special circumstances of being migrants, were observed forming closer relationships with other women of same nationality as compatriots with the experience of some having spent more and some less time in Korea.

3.2. Migrant Women and Their Husbands: Psychological Function of Sports in Conflict Resolution, Utilizing Spare Time, and Entertainment

Spousal conflict is defined as contradicting desires or disagreement in goals and expectations between a husband and a wife that emerge during marriage [26]. Migrant women in international marriages experienced much spousal conflict during their early period of marriage because of their husbands' ways of thinking and habits as well as personality differences [27]. Communication problems in particular acted as a factor that made the difficulties in the marriage more serious. As a matter of fact, migrant women in international marriages who came to Korea were not being fully accepted because of the distrust shown by their husbands and their families during the process of adapting to a new environment, culture, and language in order to become assimilated into Korean society. Such distrust and non-acceptance led to the women experiencing frustration and insecurity in their marriage.

He changed a lot from the beginning. In the beginning, he said, "I love you. I love you" often. Now he doesn't. I said I wanted to eat pineapple when I was pregnant. My husband said there's no money. When I continued to say I wanted to eat pineapple, he told me to go ask his mother to buy it. He said he didn't have money. I was brought to tears. I wanted to go home. 
When the migrant women in international marriages had recently arrived, it is interesting to note that the husbands, worried about their wives with poor Korean language skills getting lost, frequently accompanied them to the multicultural family support centers. As the age difference on average was large between the husband and the wife, at times the couple looked like a father and a daughter. The husbands were also worried and insecure about their wives because of their large age difference. Most of the concern was for the wives becoming dissatisfied with their marriage as they gained experience of the world outside the family. However, when the wives become pregnant or gave birth to children, the husbands' worries were found to dissipate somewhat. It is judged that this reflects the expectation that the wife, who is a migrant woman, will have greater responsibility for the family and children as a mother. In the sports program, a husband who brought his wife at the beginning played badminton and table tennis together, and thereafter, he attended classes, although not on a regular basis, together with his wife.

It's good to play sports together with my husband. At first, he said he didn't want to come. But now, he enjoys it. We played together last week. It's fun to play badminton with my husband, and after I nagged him to continue playing, we went to the park last week to play. But it was windy and we couldn't play properly. It's more fun to play together with my husband.

(Participant 8)

Because we do sports together, my husband doesn't complain about my cooking. Perhaps it's because that day we finished together and went to eat together. I wanted to play badminton, but since we didn't have rackets, my husband asked me to go jogging with him and I did. Playing badminton is more fun.

(Participant 8)

Although not on a regular basis, there were three husbands who participated in the program together with their wives. These wives were satisfied with the fact that they played sports together with their husbands, and as the class moved into a later stage, quite a change was felt in the attitude of their husbands. They displayed thoughtfulness in actively teaching their wives, and such scenes made other participants whose husbands did not participate envious.

$000^{\prime}$ s (Participant 8) husband is very considerate. Every Wednesday he brings her to class and afterwards he takes her home. My husband doesn't come because he's busy. $000^{\prime}$ s (Participant 8) husband is kindhearted.

It must be fun ... playing together with your husband. I asked, but my husband says he can't play badminton. Without even trying ...

(Participant 7)

Although the migrant women in international marriages found it difficult to have basic conversations with their husbands in the initial stages of their marriage due to their poor Korean, they were overcoming the problem with the care provided by their husbands and their families. The key to their effort was the continuous attempt to engage in conversation. On the days when their husbands joined them, Participants 3, 6, and 8 all laughed more and enjoyed themselves. The reason they experienced greater enjoyment when the husbands joined them in the sports program is thought to be that during the time they were playing badminton or table tennis, they were able to transcend the language barrier and share in the joy of doing an activity together as a couple. In fact, the three couples showed that all of them, the husbands and wives, were enjoying themselves throughout the class, and they testified that in addition to the class, they ended up playing sports together on weekends.

My husband is always too much in a hurry. He doesn't listen when you tell him to watch until the last moment and then hit (laughter). He says, "I know, I know," but continues to...(laughter). When we leave after this class, we talk a lot. We talk on the way back in the bus. It will be nice if all the husbands could join us next time. 
In Korea, you are told you have to be good to the husband unconditionally and respect your mother-in-law. Women are a bit more strong-willed in Thailand. In Korea, a woman is told to obey her man ... because he is the breadwinner. Everyday I'm told that. But when we play sports, there's no man or woman. That's why I like it. I can beat my husband in table tennis. He must be upset (laughter).

(Participant 1)

When participants came to class with their husbands, care was taken to allow them to spend most of the time with their husbands, and it was observed that conversations between the couples increased as a result. In badminton, the husbands guided the wives by teaching them. However, in table tennis, husbands were defeated by their wives from time to time, and whenever that happened, the women expressed delight and showed more affection toward their husbands. The increase in the extent of conversations between husband and wife, directly related to the extended opportunity for communication, was a phenomenon often observed throughout the sports program.

Jung stated that the basic cause of conflict experienced by a married couple is the social environment comprised of cultural norms, values, customs, the social system, and structure, and that that is grounded in the fixed ideas of patriarchy and male and female gender roles prevalent in Korea [28]. Indeed, this also applies to the relationship between a migrant woman in an international marriage and her husband. Migrant women in international marriages are not exempt from this analysis of marital conflict. In fact, by being a migrant, they may be more exposed and vulnerable to the elements of spousal conflict than Korean women.

Previous studies related to leisure sports such as dance sports or badminton reported that such spousal conflicts or dissatisfaction with marital life can be resolved through the husband and wife participating together in sports activities [29-31]. This can be interpreted to be due to the widened mutual understanding resulting from the process of the couple feeling a sense unity when they are immersed together in an activity with the same goal. Orthner stated that when such interaction between a couple increases, communication within the relationship will increase and understanding will be enhanced, resulting in the individuals having an opportunity to change behavior that negatively affects the marriage [32].

When couples participate in sports activities together, enjoy the experience, and share their feelings, they can be viewed as having benefited from the entertainment value of sports and also made use of the spare time function of sports [23,33,34]. As the interviews revealed, couples released some of their stress through sports activities and, during those periods, they could be seen as being harmoniously together and cooperating with each other. From this aspect, participation by married couples in sports may be an important factor in resolving spousal conflict and increasing marital and life satisfaction for migrant women in international marriages and their families; therefore, such participation should be actively encouraged.

\subsection{Social Empowerment of Migrant Women with the Physical and Psychological Functions of} Sports: Physical Image, Utilizing Spare Time, and Resolving Stress

For most migrant women in international marriages, marriage is arranged rather than based on dating or courtship. The majority of these women are from developing countries with a relatively low per-capita income, such as Mongolia, the Philippines, and Vietnam. For women who arrive in Korea through marriage, Korean culture is learned by inculcation rather than natural conveyance through life experience, and as such, they encounter much cultural conflict and feel substantial burdens and pressures. In particular, women from countries unfamiliar with the patriarchal Korean culture frequently experience marital troubles with their husbands and in-laws, and some women are also found to have suffered verbal and physical abuse at the hands of their husbands. Korean society has strict adherence to norms for women as wives, daughters-in-law, and mothers. In such a process, the women find that the status they occupy is relatively narrow. 
In addition, they feel a great burden trying to live the role of a Korean woman, and along with this, suffer additional stress due to being unfamiliar with the Korean language and Korean culture. Some women seriously agonize over whether such factors prevent them from continuing their marriage. To them, "leisure activity" is a luxury, far removed from the concept generally held by and accepted in the Korean society.

Leisure activity? What's that? Ah ... When I have time to spare, I usually look for work. I have to make money, even a small amount. I'm a bit frustrated since there's nothing I can do in Korea. I can't speak the language well ... I look for part-time jobs, and if there's a position open, I take it. I can't make time to learn a new skill. As for any learning, I take a Korean class and a computer class at the multicultural family support center; that's about it ... When I have time, I meet friends (compatriots) ... we talk about our husbands and babies. That's about it ...

(Participant 9)

As I told you, I would like to travel and play sports. But that is hard to do. When I try, there's no place to do it and I don't know where to go ... I played badminton once with my husband at the park; that was the only time. I want to do more, but I end up not doing it ...

(Participant 1)

Participant 7 , who travelled often before getting married, was unable to have such a life in Korea. As discussed above, the reason for this was that most of her time was allocated to doing housework and learning Korean language and culture.

I really like travelling. I visited many places all over China. Before getting married, I even went to the top of Mount Baekdu ... all by myself. But after marriage, I can't go anywhere. My husband seems not to like it... he says we'll go, but last summer we didn't even go on a vacation. We had planned to do so, but my husband became too busy ...

(Participant 7)

There are currently over 200 multicultural family support centers, including civilian organizations, that provide information and services needed by migrant women in international marriages for life in Korea. However, most of these centers lean too much on providing only basic information and minimal Korean language and culture instruction needed for Korean life. From the aspect of providing information and adding convenience to life in Korea, this is very encouraging and positive. On the other hand, there is also a negative aspect of the multicultural family center acting as a fence, keeping these women from fully taking part in Korean society.

It can be said there is a demand for the multicultural family support center to actively provide opportunities and promote self-realization rather than serving as a place for passive information delivery and study of Korean culture. Considered in light of earlier studies criticizing multiculturalism in the role of inculcating Korean culture rather than promoting the sharing and exchange of different cultures based on mutual respect, the multicultural family support center as a passive and closed space needs to change into a more active and open one. In the interview of the study participants, it was possible to confirm the factors contributing to their self-esteem and social cohesion. For the multicultural family support center, together with its role as a resource for providing information to women who are migrating to Korea for the first time, the path of serving as an arena for their self-realization and enjoyment of leisure activities needs to be explored.

It's good to come here (multicultural family support center) and exercise. It's the only place I want to come to. I exercise and talk with others - I think it's good. And I think I'll really lose a lot of weight, if I do it daily ... I envy Korean women who are slim.

(Participant 6)

You know there are yoga and dance sports. It'd be nice if I can learn things like that. I never thought about doing something like that at the center... after listening to you, 
it would be nice. Since it would be hard for me to make extra time and pay money to learn, having a yoga class like the Korean language class will be nice. A lot of people will sign up. They say it's good for maintaining your figure after giving birth.

(Participant 7)

Meanwhile, Participant 10 suffered from serious domestic violence perpetrated by her husband. She considered the day when she came to the sports program as her only time of liberation during the week. Participant 10 had very poor Korean language skills, and after getting married at a young age, she felt dissatisfied with the communication with her husband, who was much older. Suffering from her husband's drunken outbursts and violence, she left home during the latter part of the program and could not even participate in the program. She said she had wanted to become a physical education teacher when she was in the Philippines but came to Korea after getting married. She was very regretful of coming to Korea. Among the participants, she displayed the best athletic ability and gameplaying skills during class, but when it was time to return home after class, her expression always became very dark. For her, the multicultural sports program was a liberation and escape from her home life. She was reluctant to associate with other migrant women in international marriages during the program and spoke honestly about her situation only to the researcher. The reason for this was that if the story about her dissatisfaction reached her husband, it would lead to more violence and abuse at home. The talks she had with the researcher were like appeals and took place mainly during the table tennis matches.

According to O'Neal and Dishman, regular exercise and physical activity reduce depression regardless of age, gender, race, and socio-environmental conditions, and such benefits appear for all participants regardless of the exercise goal $[35,36]$. If exercise is of longer duration and performed more frequently, the effect of depression reduction is increased. From the examination of attendance in other programs administered during a given week, Participant 10 was found to have high absenteeism. However, for the sports program, she was always first to arrive and actively participated in the events, and at least during the class period, she appeared to be happy.

Multicultural families are clearly Korean citizens and members of the nation; however, having low social status as well as low income and education level are the reality of most multicultural families today, and it is also a reality that, due to those reasons, members do not enjoy full social benefits or rights. Kymlica also reported that minorities in a mainstream society experience difficulties in having and enjoying adequate leisure time due to such reasons as their educational and economic situations [37]. Although Koreans or Mexicans living in the United States cannot be readily compared to migrant women living in South Korea, these groups may have similar circumstances that limit their leisure time, and that is worth examining.

From this aspect of research, active establishment of leisure and sports activity programs at multicultural family support centers will positively affect the experience of migrant women in international marriages in adapting to Korean life. Furthermore, these programs will also help in improve the quality of life of the participants.

\section{Conclusions}

This study began from the question of what impact the social integration function of sports has on the social integration of migrant women in international marriages in the current circumstances of Korea, as the country is becoming more multicultural with a sharp increase in the number of foreign migrants. To address this question, the programs of multicultural family support centers nationwide were analyzed to find which programs were being administered in order to promote social integration. In addition, badminton and table tennis classes were also run for seven months, with 20 migrant women in international marriages as the participant subjects, and the resulting trend of changes in the participants attending the classes was observed.

The participants in this study comprised migrant women in international marriages in their $20 \mathrm{~s}$ to $40 \mathrm{~s}$. Along with these women, three Korean college students also participated 
in the study. With the support of S Multicultural Family Support Center, a multicultural sports program was run for seven months, from May to November 2009. The researcher participated in and observed the entire course of the program. Data were collected through in-depth interviews with the participants.

An investigation of the multicultural family support centers nationwide showed that Korean language and culture education programs made up the bulk of the programs offered by the centers. Programs to promote social integration tended to be piecemeal and were found to consist mostly of one-off events such as family sports events. No center offered a sports program on a regular basis. From the analysis of the effect of the multicultural sports program based on the information collected through the observation notes, self-assessment journals, camcorder recordings, and in-depth interviews, it was learned that migrant women in international marriages experienced many changes in their social relationships as a result of participating in the multicultural sports program.

In terms of the relationships among the migrant women in international marriages themselves, the multicultural sports program was found to also develop into a type of self-help meeting, and through this space, an overall exchange of information about Korean life took place. Concerning the relationship between the women and their husbands, the sports activity was found to be helpful for spousal communication and understanding. The sports activity provided a forum for conversation between the participating husband and wife. Moreover, in the relationship between the women and their children, the sports program was used by the mothers as a space for interacting and sharing empathy with their children and for educating the children.

In the relationship between the women and the native Koreans, the program provided an opportunity for the Koreans to discard the prejudices and preconceptions they had about migrant women in international marriages, and for the women, it served as a space to make Korean friends and an opportunity to gain confidence in Korean life.

Finally, the multicultural sports program was found to also play a positive role in the leisure activity of the migrant women in international marriages. The non-language qualities of sports allowed the women to easily interact with other women of different nationalities, including Koreans, and to enjoy the games. In addition, through this process it was found that they relieved stress and felt satisfied with the activity.

Author Contributions: Conceptualization, S.-J.L. and I.-S.Y.; data curation, B.-W.A.; formal analysis, B.-W.A.; investigation, I.-S.Y.; methodology, S.-J.L. and B.-W.A.; project administration, S.-J.L.; supervision, I.-S.Y.; validation, B.-W.A.; visualization, I.-S.Y.; writing—original draft, S.-J.L.; writing—review and editing, B.-W.A. All authors have read and agreed to the published version of the manuscript.

Funding: This research received no external funding.

Institutional Review Board Statement: The study was conducted according to the guidelines of the Declaration of Helsinki, and approved by the Yonsei University Department of Sports Science Research Institutional Review Board.

Informed Consent Statement: Informed consent was obtained from all subjects involved in the study.

Data Availability Statement: Not applicable.

Conflicts of Interest: The authors declare no conflict of interest.

\section{References}

1. Statistics Korea. Available online: https://kosis.kr/statHtml/statHtml.do?orgId=101\&tblId=DT_1TS2001 (accessed on 5 May 2010).

2. International Federation for Human Rights. Available online: https://www.fidh.org/en/region/asia/south-korea/UN-CERDurges-the-Republic-of (accessed on 23 August 2010).

3. Kwon, S.-Y. Sports policy direction in a multicultural society: Sports Science Korean physical education association for women, Sports policy direction in a multicultural society. Korean J. Sports Sci. 2008, 6, 17-29.

4. Uhm, H.-J. Migration in the global age and issues in Korean multicultural society Korean sociological association. Korean J. Sociol. 2007, 1, 39-69.

5. Yun, I.-J. State led multiculturalism and citizen led multiculturalism. Korean J. Sociol. 2007, 8, $251-291$.

6. Kwon, M.-H. Sports policy direction in a multicultural society. Korean J. Sport Sci. 2008, 30, 2-8. 
7. Coakley, J.-J. Sport in Society: Issues and Controversies; Times Mirror, Mosby College Ppublishing: St. Louis, MI, USA, 2021.

8. Muller, F.; Zoonen, L.; Roode, L. The integrative power of sport: Imagined and real effects of sport events on multicultural integration. Sociol. Sport J. 2008, 25, 387-401. [CrossRef]

9. Henry, I.; Radzi, W.; Rich, E.; Shelton, C.; Theodoraki, E. White, Women, Leadership and the Olympic Movement; Institute of Sport and Leisure Policy; Loughborough University \& the International Olympic Committee: Loughborough, UK, 2004.

10. Karin, K.-F.; Peter, K.; Eva-Carin, L. Integration into and through sports? Sport-activities for migrant children and youths. Eur. J. Sport Soc. 2021, 18, 64-81.

11. Sine, A.; Annette, M.-C. Govering integration through sports. Nord. J. Migr. Res. 2012, 2, $26-34$.

12. Swagler, M.-A.; Jome, L.R.-M. The effects of personality and acculturation on the adjustment of North American Sojourners in Twaiwan. J. Couns. Psychol. 2005, 2, 527-536. [CrossRef]

13. Geoff, P.; Judy, P. Key Concepts in Social Research; SAGE: London, UK, 2004.

14. Lee, T.-S. A Study on the Social Integration due to the Foreign Workers' Problems in Japan. Unpublished. Master's Thesis, Boo-kyung University, Seoul, Korea, 2008.

15. Yun, T.-N. Qualitative Research Methodology; Arche: Seoul, Korea, 2004; pp. 76-81.

16. Ju, S.-H. A Study on the Posttraumatic Growth of Divorced Family's Children. Korean J. Fam. Soc. Work 2015, 9, 97-131.

17. Patton, M.-Q. Qualitative Research E Evaluation Methods, 3rd ed.; Sage: Thousand Oaks, CA, USA, 2002.

18. Noh, Y.-K.; Lee, C.-W. Research Methodology in Leisure Studies; Dae-kyung Books: Seoul, Korea, 2003.

19. Yin, R.-K. Case Study Research: Design and Methods, 3rd ed.; Sage: Thousand Oaks, CA, USA, 2003.

20. Morelli, N.; Barello, S.; Mayan, M.; Graffigna, G. Supporting family caregiver engagement in the care of old persons living in hard to reach communities: A scoping review. Health Soc. Care Community 2019, 27, 1363-1374.

21. Miles, M.-B.; Huberman, A.-M.; Saldana, J. Qualitative Data Analysis: A methods Sourcebook, 3rd ed.; Sage: Los Angeles, CA, USA, 1985; pp. 56-71.

22. King, D.; Le Galès, P.; Vitale, T. Assimilation, Security, and Borders in the Member States. In Reconfiguring European States in Crisis; Oxford University Press: Oxford, UK, 2017; pp. 428-450.

23. Choi, H.-H.; Kim, W.-S. Sports as Foreign Students' Road to Academic Engagement: Exploration of Sports as Educational Function from the Viewpoint of Foreign Asian Students in Korea's Local Universities. Korean J. Sports Sci. 2020, 2, 513-524. [CrossRef]

24. Donga. Available online: https://news.naver.com/main/read.naver?mode=LSD\&mid=sec\&sid1=102\&oid=020\&aid=0002174864 (accessed on 16 October 2010).

25. Kim, Y.-J. The effect of participation motivation in leisure sports and leisure satisfaction on health satisfaction of the elderly. $J$. Korean Soci. Sports Sci. 2009, 18, 363-373.

26. Park, R.-Y.; Kim, B.-Y. The relations among motivation leisure satisfaction and quality of life for the elderly women participants in dance sports. J. Korean Assoc. Phys. Educ. Sport Girls Women 2009, 23, 133-146.

27. Colman, D.-H.; Straus, M.-A. Physical Violence in American Families: Marital power, conflict, and violence in a nationally representative sample of American couples. In Physical Violence in American Families; Straus, M., Gelles, R., Eds.; Transaction Publishers: Franklin, NJ, USA, 1990; pp. 122-135.

28. Jung, M.-H. An Empirical Study of the Social Adjustment stressed of Immigrant Women. Int. Area Stud. Rev. 2011, 15, 451-481.

29. Choi, M.-E. The Relationship Between the Participation Degree in Dance Sports by Husband and Wife, Marital Intimacy and Marriage Satisfaction. Korean J. Sports 2011, 9, 49-60.

30. Huh, J.-Y.; Jung, S.-J. The Relationship between Flow Experience, Relationship of Married Couple and Quality of Life. Danc. Res. J. Korea 2009, 6, 253-268.

31. Cho, T.-E.; Cho, S.-S. A Study on Married Women's Sports Participation, Management of Marital Conflict, and Marital Satisfaction. Korean J. Phys. Educ. 2021, 5, 163-176. [CrossRef]

32. Orthner, D.-K. Leisure activity patterns and marital satisfaction over the marital career. J. Marriage Fam. 1974, 37, 91-102. [CrossRef]

33. Seo, J.-B.; Park, H.-W.; Kim, S.-I. Character Education Through School Physical Education: School Culture and the Role of Sports. Korea J. Sports 2019, 17, 521-530.

34. Wi, S.-S. Introduction to Community Sports; Dae-kyong Books Publishers: Seoul, Korea, 2004; pp. 54-72.

35. Neal, H.-O.; Dishman, R.-K. Physical Activity and Depression: A Quantitative Synthesis; The University of Georgia: Athens, Greece, 2002; pp. 69-83.

36. North, T.-C.; McCullah, P. Aerobic and Anaerobic Exercise as a Treatment for Depression: Meta-Analysis; Association for the Advancement of Applied Sport Psychology: Nashua, NH, USA, 1988; pp. 96-108.

37. Kymlica, W. Multiculturalism in Asia; Oxford University Press: New York, NY, USA, 2005; pp. 84-99. 